\title{
Differences in Peripheral Blood Lymphocytes between Brand-Name and Generic Tacrolimus Used in Stable Liver Transplant Recipients
}

\author{
Jong Man Kim ${ }^{\mathrm{a}}$ Choon Hyuck David Kwon ${ }^{\mathrm{a}}$ Jae-Won Joh ${ }^{\mathrm{a}}$ Dong Hyun Sinn ${ }^{\mathrm{b}}$ \\ Gyu-Seong Choi ${ }^{a}$ Jae Berm Park ${ }^{a}$ Eun-Suk Kang ${ }^{c}$ Suk-Koo Lee ${ }^{a}$ \\ ${ }^{\mathrm{a}}$ Department of Surgery, ${ }^{\mathrm{b}}$ Division of Gastroenterology, Department of Medicine, and ${ }^{\mathrm{c}}$ Department of \\ Laboratory Medicine and Genetics, Samsung Medical Center, Sungkyunkwan University School of Medicine, \\ Seoul, Republic of Korea
}

\section{Significance of the Study}

- In this study, peripheral blood lymphocytes were compared between stable liver transplant recipients receiving brand-name and generic tacrolimus. The level of CD4+Foxp3+ T cells was higher in the brand-name than in the generic tacrolimus group after transplantation. This study found that brandname tacrolimus could have more potential immunosuppressive activity than generic tacrolimus regarding the contribution of CD4+Foxp3+ T cells to graft tolerance in liver transplant recipients.

\section{Keywords}

Liver transplantation $\cdot \gamma \delta T$ cells $\cdot$ Regulatory T cells $\cdot$ Stable graft function · Living donors

\begin{abstract}
Objectives: In this study, peripheral blood lymphocytes were compared between a brand-name and a generic tacrolimus group in stable liver transplant recipients. Subjects and Methods: Sixteen patients who underwent ABO-compatible living donor liver transplants between 2012 and 2013 and had stable graft function were included in this study. Ten patients received brand-name tacrolimus and 6 patients received generic tacrolimus. CD3, CD4, CD8, $\gamma \delta, C D 4+F o x P 3+$, and CD3-CD56+ T cells were analyzed in peripheral blood obtained preoperatively and 4, 8, 12, and 24 weeks after liver transplantation. Categorical variables were compared using a $x^{2}$ test or Fisher exact test, and continuous variables were
\end{abstract}

compared using the Mann-Whitney U test. Results: Regarding the baseline and perioperative characteristics, there were no statistically significant differences between the 2 groups. Immunosuppression also was not different. Subtype analysis of T-cell populations carried out in parallel showed similar levels of $C D 3, C D 4, C D 8$, and $\gamma \delta T$ cells with brand-name tacrolimus and generic tacrolimus in stable liver transplant recipients. However, the levels of CD4+Foxp3+ and CD3-CD56+ T cells were higher in the brand-name tacrolimus group than in the generic tacrolimus group 8 weeks after transplantation $(p<0.05)$. Conclusions: The level of CD4+Foxp3+ T cells was higher in the brand-name tacrolimus group than in the generic tacrolimus group after transplantation. This finding showed that brand-name tacrolimus could have more potential immunosuppressive activity than generic tacrolimus regarding the contribution of CD4+Foxp3+ T cells to graft tolerance in liver transplant recipients.

ㄷ 2017 S. Karger AG, Basel

\begin{tabular}{|c|c|}
\hline KARGER & $\begin{array}{l}\text { Karger } \\
\text { Openaccess }\end{array}$ \\
\hline $\begin{array}{l}\text { E-Mail karger@karger.com } \\
\text { www.karger.com/mpp }\end{array}$ & $\begin{array}{l}\text { This is an Open Access article licensed under the terms of the } \\
\text { Creative Commons Attribution-NonCommercial 3.0 Un- } \\
\text { ported license (CC BY-NC) (www.karger.com/OA-license), } \\
\text { applicable to the online version of the article only. Distribu- } \\
\text { tion permitted for non-commercial purposes only. }\end{array}$ \\
\hline
\end{tabular}

Prof. Jae-Won Joh, MD, PhD

Department of Surgery, Samsung Medical Center

Sungkyunkwan University School of Medicine

Irwon-Ro 81, Gangnam-Gu, Seoul, 135-710 (Republic of Korea)

E-Mail jw.joh@samsung.com 


\section{Introduction}

Tacrolimus is one of the most commonly used medications for the prevention of liver allograft rejection. Tacrolimus acts as an immunomodulatory agent by blocking the transcription of the gene encoding interleukin-2 (IL2 ) that is essential for T-cell-mediated immune response $[1,2]$.

Most countries have tried to reduce the cost of care for transplant patients, but the financial burdens of immunosuppressive therapy remain high [3]. This situation has led to the development and wide usage of generic tacrolimus, which has met all standards for bioequivalence and is therapeutically equivalent to brand-name tacrolimus $[4,5]$. Many recipients had received generic tacrolimus after the expiration of the tacrolimus patent. Generic drugs offer significant cost savings for liver transplant programs and recipients; however, there has been considerable concern among transplant hepatologists and patients about the equivalence of the generic and brandname forms $[3,6]$. Given the lack of adverse events reported and the associated cost savings, conversion from brand-name to generic tacrolimus has been encouraged in organ transplantation [4].

$\alpha \beta T$ lymphocytes play a central role in several experimental models of allograft rejection and tolerance, acting as both effector and suppressor T cells [7]. Many studies have demonstrated that the T helper (Th)1/Th2 cell balance [8], natural killer (NK) cells [9], NKT cells [10], Foxp3+ regulatory T cells (Tregs) [11], and Th17 cells [12] are involved in graft function such as rejection or tolerance. Recently, $\gamma \delta \mathrm{T}$ cells were also reported to be associated with liver allograft tolerance [13]. Human $\gamma \delta \mathrm{T}$ cells are composed of 2 main subsets, such as V $\delta 1$ and $\mathrm{V} \delta 2$, according to the rearranged $\mathrm{V} \delta$ chain. $\mathrm{V} \delta 1 \gamma \delta \mathrm{T}$ cells, which are predominant in the spleen, intestine, and liver, possess regulatory and effector properties, but V $\delta 2 \gamma \delta \mathrm{T}$ cells, which are the main subset of $\gamma \delta$ T cells in the peripheral blood, possess defense properties against pathogens [7]. Several studies have reported that a preponderance of $\mathrm{V} \delta 1 \gamma \delta \mathrm{T}$ cells is associated with liver allograft acceptance [14-16].

Some studies have described the safety and efficacy of generic tacrolimus in liver transplant recipients $[5,17]$. However, the analysis of peripheral lymphocytes in blood between patients treated with brand-name and generic tacrolimus has not been done. Hence, in this study, the peripheral blood lymphocytes in brand-name and generic tacrolimus were compared in stable liver transplant recipients.

\section{Subjects and Methods}

\section{Patients}

Sixty-four patients underwent ABO-compatible liver transplantation between 2012 and 2013. All patients were cytomegalovirus seropositive and received a right lobe graft from a living donor. All recipients received tacrolimus as a calcineurin inhibitor. The study was approved by the Samsung Medical Center's Institutional Review Board in Seoul. The exclusion criteria were recipients of cyclosporine, sirolimus, or everolimus, as well as patients with bile duct complications, cytomegalovirus infection, biopsyproven acute rejection, hepatocellular carcinoma recurrence, graft failure, or who died. Sixteen patients were selected because they had stable graft function without complications. Ten patients received brand-name tacrolimus (Prograf ${ }^{\circledR}$; Astellas Pharma, Tokyo, Japan), while 6 patients received generic tacrolimus (Tacrobell ${ }^{\circledR}$; Chong Kun Dang Pharma, Seoul, Korea). One surgeon used brand-name tacrolimus and the other surgeon used generic tacrolimus because they prescribed their favorite medication. All demographic and clinical data were obtained from medical records. All patients were followed for the first 24 weeks after living donor liver transplantation (LDLT).

\section{Immunosuppression}

The immunosuppressive protocol of our center was used as described previously [18]. Basiliximab (20 $\mathrm{mg}$ ) was used as an induction agent. All patients were infused with prostaglandin $\mathrm{E}_{1}$, gabexate mesilate, and methylprednisolone. Maintenance immunosuppressive therapy consisted of corticosteroids, tacrolimus, and mycophenolate mofetil (MMF). Corticosteroids were withdrawn 3 months after transplantation.

\section{Peripheral Blood Lymphocyte Subpopulations}

Lymphocytes were analyzed in fresh whole blood samples obtained preoperatively and $4,8,12$, and 24 weeks after liver transplantation. For lymphocyte subset analysis using multicolor flow cytometry, whole blood was incubated with various monoclonal antibodies specific for lineage CD markers according to the manufacturer's instructions [19]. All monoclonal antibodies were purchased from eBioscience (San Diego, CA, USA), BD Biosciences (Franklin Lakes, NJ, USA), or Thermo Fisher Scientific (Rockford, IL, USA). The cocktail for $\gamma \delta$ T cells consisted of CD3PerCP Cy5.5 (SK7, eBioscience), CD4-APC-eFluor780 (RPA-T4, eBioscience), CD8-PE-Cy7 (SK1, eBioscience), TCR V delta 1-FITC (TS8.2, Thermo Fisher Scientific), and V82 TCR-PE (B6, BD Biosciences). The cocktails for Tregs and NK cells were as follows: CD4-PerCP Cy5.5 (RPA-T4, eBioscience), CD25-APC (BC96, eBioscience), and FOXP3-PE (PCH101, eBioscience) for Tregs, and CD3-PerCP Cy5.5 (SK7, eBioscience), CD16-APCH7 (3G8, BD Biosciences), and CD56-FITC (MEM188, eBioscience) for NK cells. Briefly, $100 \mu \mathrm{L}$ of whole blood containing different combinations of antibodies was incubated for $15 \mathrm{~min}$ at room temperature in the dark. This was followed by red blood cell lysis and washing in phosphate-buffered saline (PBS). Cells were reconstituted with PBS containing $0.5 \%$ albumin, and FACS acquisition for cell surface staining analysis was performed. For intracellular staining, surface stained cells were fixed and permeabilized with Fix/Perm reagent (eBioscience) and then incubated with anti-Foxp3 antibody. Various lymphocyte subsets were defined as follows: CD3+CD4+ for helper $\mathrm{T}$ cells, 
Table 1. Recipient characteristics of the brand-name and generic tacrolimus groups in living donor liver transplantation

\begin{tabular}{|c|c|c|c|}
\hline & $\begin{array}{l}\text { Brand-name } \\
\text { tacrolimus }(n=10)\end{array}$ & $\begin{array}{l}\text { Generic } \\
\text { tacrolimus }(n=6)\end{array}$ & $p$ value \\
\hline \multicolumn{4}{|l|}{ Baseline } \\
\hline Sex (male) & $9(90 \%)$ & $5(83.3 \%)$ & 0.696 \\
\hline Age, years & $56(44-68)$ & $48(40-67)$ & 0.368 \\
\hline \multicolumn{4}{|l|}{ Diagnosis } \\
\hline Alcoholic & $0(0 \%)$ & $1(16.7 \%)$ & \\
\hline $\mathrm{HBV}$ & $2(20 \%)$ & $1(16.7 \%)$ & \\
\hline $\mathrm{HBV}, \mathrm{HCC}$ & $8(80 \%)$ & $2(33.3 \%)$ & \\
\hline $\mathrm{HCV}, \mathrm{HCC}$ & $0(0 \%)$ & $1(16.7 \%)$ & \\
\hline NBNC & $0(0 \%)$ & $1(16.7 \%)$ & 0.176 \\
\hline \multicolumn{4}{|l|}{ History } \\
\hline Hypertension & $1(10 \%)$ & $0(0 \%)$ & 0.424 \\
\hline Diabetes & $2(20 \%)$ & $1(16.7 \%)$ & 0.869 \\
\hline Child-Pugh class & & & 0.801 \\
\hline A & $6(60 \%)$ & $3(50 \%)$ & \\
\hline $\mathrm{B}$ & $2(20 \%)$ & $2(33.3 \%)$ & \\
\hline $\mathrm{C}$ & $2(20 \%)$ & $1(16.7 \%)$ & \\
\hline MELD score & $8(7-42)$ & $9(7-19)$ & 0.875 \\
\hline \multicolumn{4}{|l|}{ Perioperative } \\
\hline Macrosteatosis, \% & $5(1-5)$ & $5(5-10)$ & 0.313 \\
\hline GRWR & $0.96(0.79-1.26)$ & $1.25(0.89-1.26)$ & 0.127 \\
\hline Operative time, $\min$ & $532(424-725)$ & $539(441-604)$ & 0.833 \\
\hline Cold ischemic time, $\min$ & $76(47-117)$ & $95(57-106)$ & 0.366 \\
\hline Warm ischemic time, min & $33(20-50)$ & $26(14-55)$ & 0.445 \\
\hline Intensive care unit stay after transplantation, $\mathrm{n}$ (days) & $6(4-7)$ & $6(5-7)$ & 0.755 \\
\hline Hospitalization, $\mathrm{n}$ (days) & $22(21-28)$ & $22(17-24)$ & 0.755 \\
\hline \multicolumn{4}{|l|}{ Immunosuppression } \\
\hline Tacrolimus concentration at 3 months & $5.5(2.8-13.9)$ & $5.3(2.3-12.4)$ & 0.788 \\
\hline MMF at 3 months & $7(70 \%)$ & $4(66.7 \%)$ & 0.889 \\
\hline Steroids at 3 months & $7(70 \%)$ & $5(83.3 \%)$ & 0.551 \\
\hline
\end{tabular}

Values are presented as $n$ (\%) or medians (range). HBV, hepatitis B virus; HCC, hepatocellular carcinoma; HCV, hepatitis C virus; NBNC, non-B non-C; MELD, Model for End-Stage Liver Disease; GRWR, graft-torecipient weight ratio; MMF, mycophenolate mofetil.

CD3+CD8+ for cytotoxic T cells, CD3-CD56+CD16+ for NK cells, and TCR V $\delta 1$ and V $\delta 2$ for CD3+CD4-CD8- $\gamma \delta \mathrm{T}$ cells. Cells were analyzed on a FACSCanto II using FACSDIVA software (BD Biosciences).

\section{Statistical Analysis}

Categorical variables were compared using a $\chi^{2}$ test or Fisher exact test and were expressed as percentages. Continuous variables were compared using the Mann-Whitney $U$ test and were expressed as medians and ranges. Repeated measures of lymphocyte populations after LDLT were analyzed using a mixed model. Absolute counts at each point after transplantation were compared using the Mann-Whitney $\mathrm{U}$ test with Bonferroni correction. Statistical significance was defined as $p<0.05$. Data analysis was performed using SPSS 21.0 (IBM Corp., Armonk, NY, USA).

Brand-Name and Generic Tacrolimus

\section{Results}

\section{Baseline Characteristics}

The baseline characteristics of the patients are summarized in Table 1 . There were no statistically significant differences in diagnosis, gender, age, history of hypertension, or diabetes, in Child-Pugh class, or in Model for End-Stage Liver Disease (MELD) scores between the 2 groups. Operative time, macrosteatosis, cold and warm ischemic time, graft-to-recipient weight ratio, stay in intensive care unit after LDLT, and hospitalization did not reach significance in the perioperative period. The proportions of MMF and steroids in the brand-name and generic tacrolimus groups at 3 months after LDLT were 


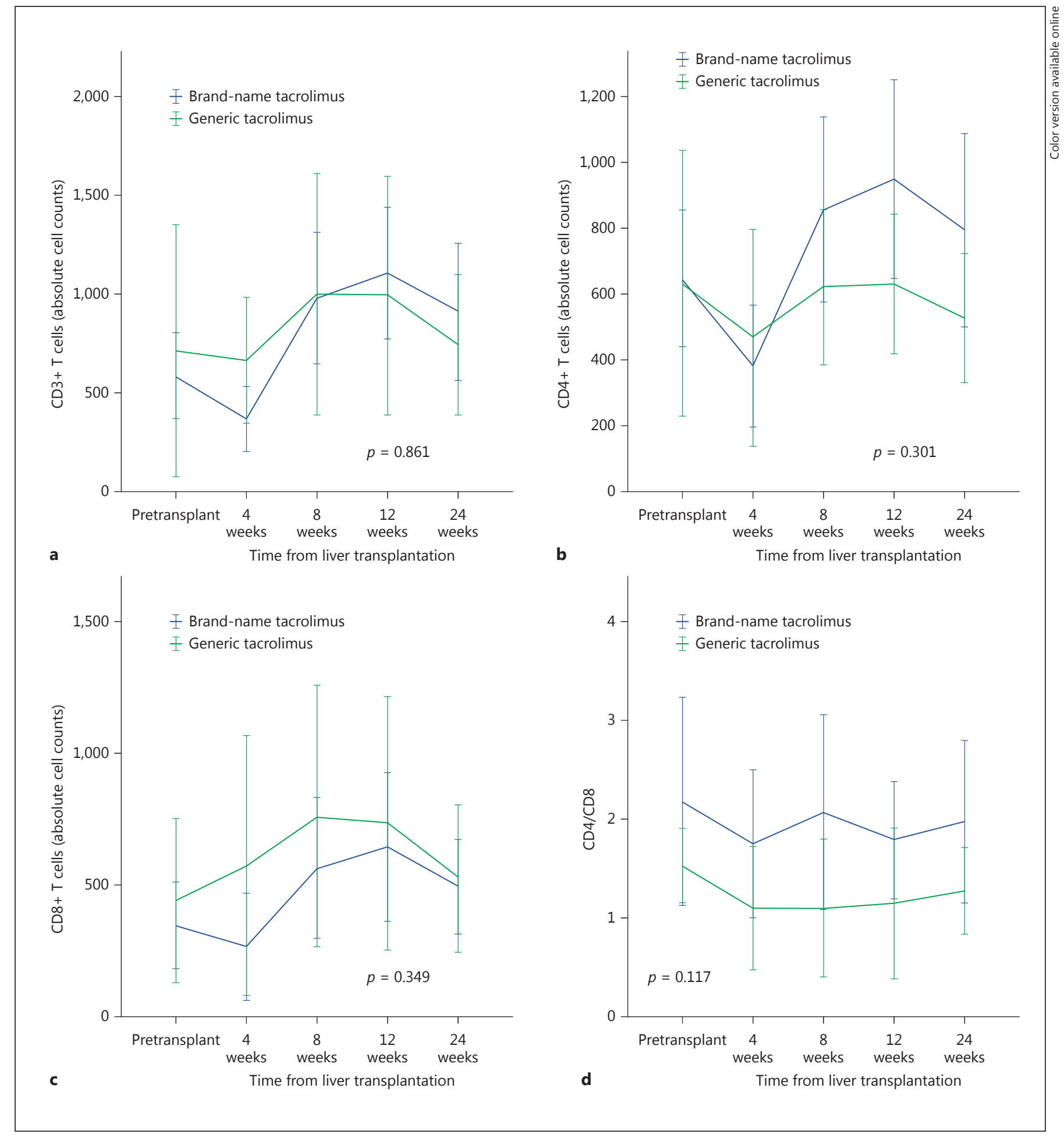

Fig. 1. Changes in a $\beta \mathrm{T}$ cells after living donor liver transplantation: CD3+ T cells (a), CD4+ T cells (b), CD8+ T cells (c), and CD4/CD8 ratio (d). 


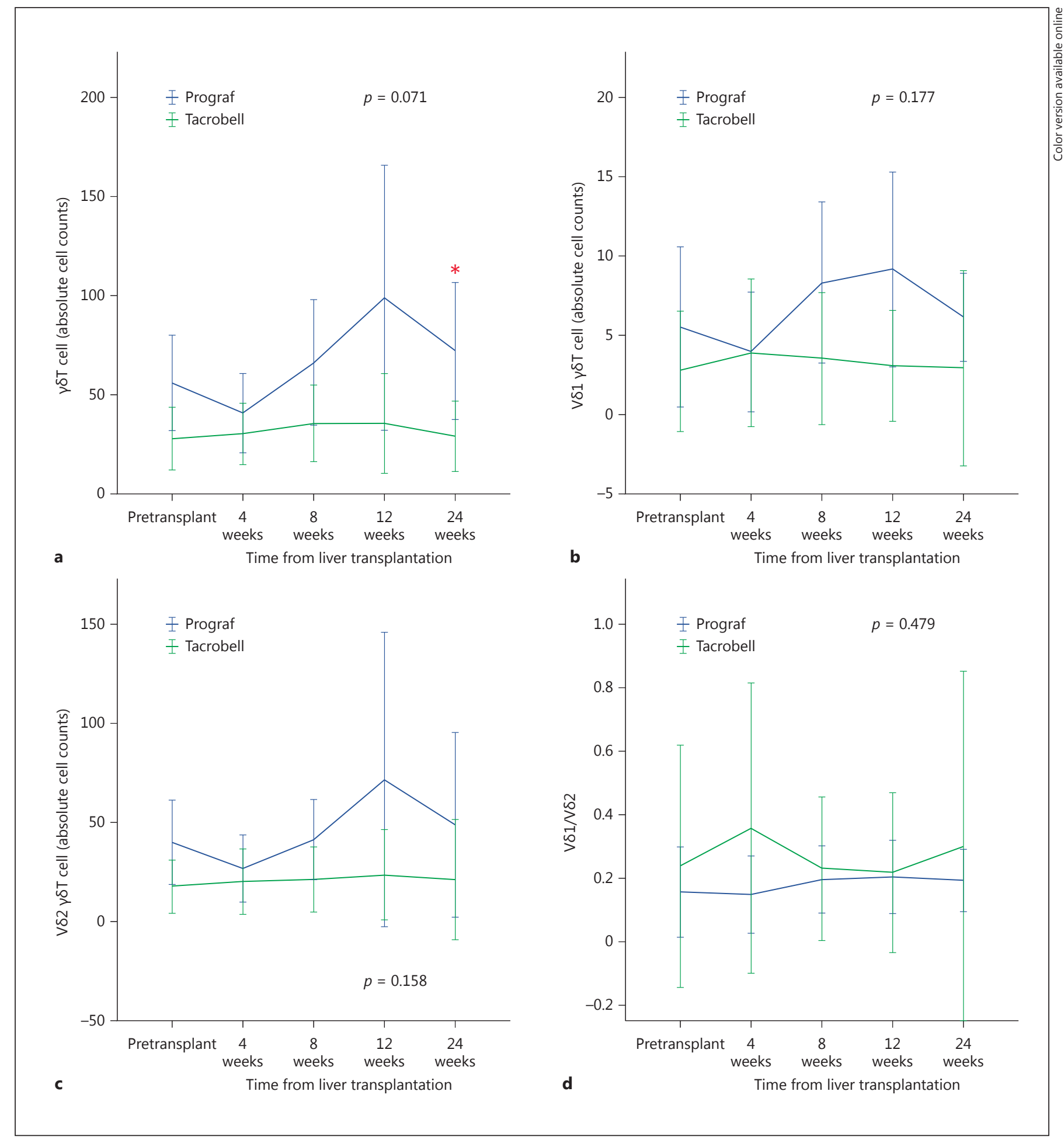

Fig. 2. Changes in $\gamma \delta \mathrm{T}$ cells after living donor liver transplantation: $\gamma \delta \mathrm{T}$ cells (a), V $\delta 1 \gamma \delta \mathrm{T}$ cells (b), V $\delta 2 \gamma \delta \mathrm{T}$ cells (c), and $\mathrm{V} \delta 1 / \mathrm{V} \delta 2$ ratio (d). 


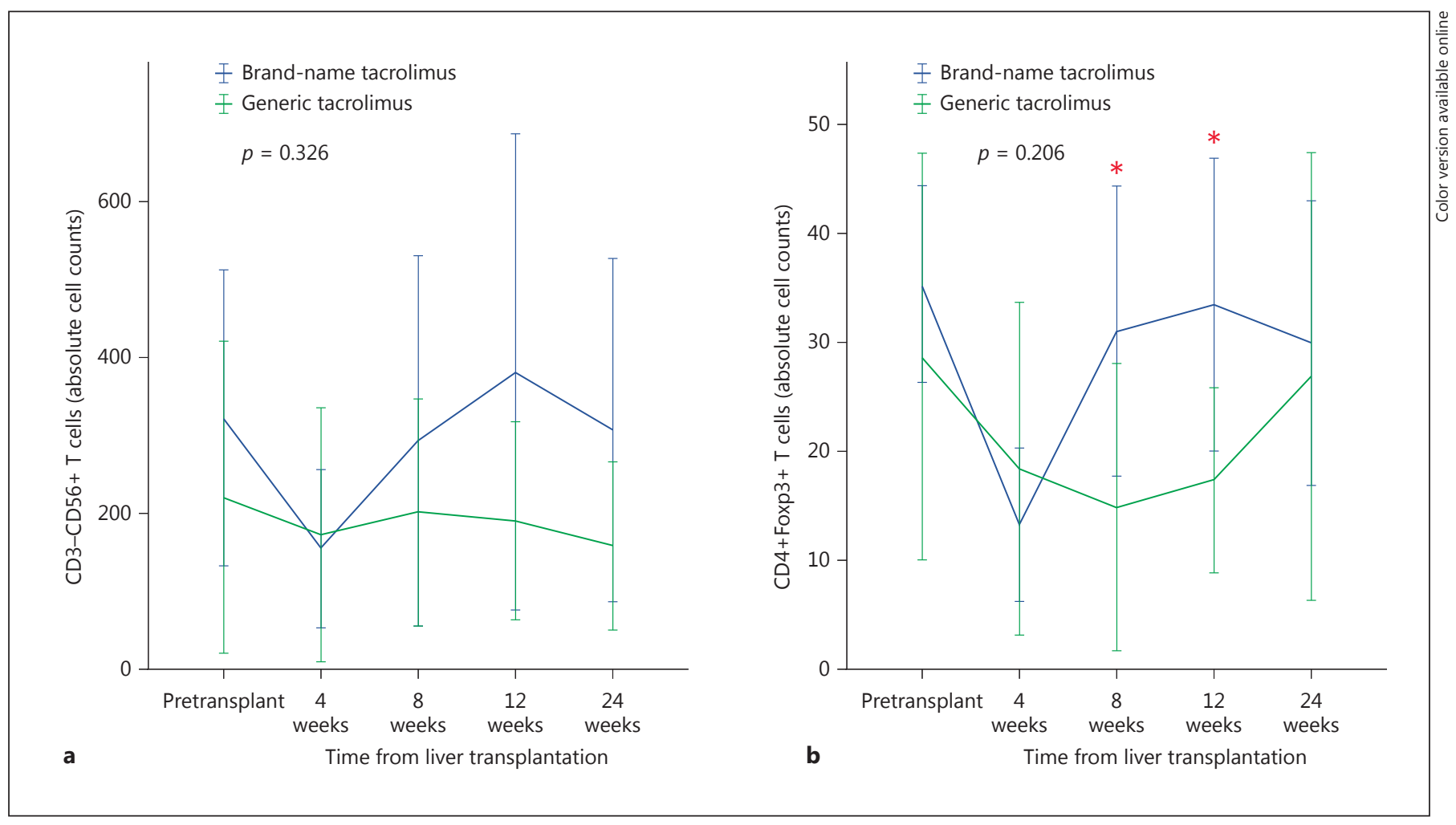

Fig. 3. Changes in CD3-CD56+ T cells (a) and CD4+FoxP3+ T cells (b) after living donor liver transplantation.

similar ( 70 vs. $66.7 \%$ for MMF and 70 vs. $83.3 \%$ for steroids, respectively). In addition, the concentration of tacrolimus in the brand-name and generic tacrolimus groups was 5.5 and $5.3 \mathrm{ng} / \mathrm{dL}$, respectively $(p=0.8)$

Peripheral Blood T-Cell Subsets between Brand-Name and Generic Tacrolimus

The absolute lymphocyte counts and absolute cell counts of CD3 + T cells after LDLT were increased after 8 weeks (Fig. 1). The absolute lymphocyte counts and absolute cell counts of CD3+ T cells in the brand-name tacrolimus group did not vary from those in the generic tacrolimus group. In subgroup analysis, absolute cell counts of CD4+ $\mathrm{T}$ cells in the brand-name tacrolimus group were generally higher than in the generic tacrolimus group after 8 weeks, but absolute cell counts of CD8+ $\mathrm{T}$ cells in the generic tacrolimus group were higher than in the brand-name tacrolimus group (Fig. 1). The CD4/ CD8 ratio in the brand-name tacrolimus group was higher than in the generic tacrolimus group after LDLT.

Absolute cell counts of $\gamma \delta \mathrm{T}$ cells in the brand-name tacrolimus group were higher than in the generic tacroli- mus group (Fig. 2). Absolute cell counts of $\gamma \delta \mathrm{T}$ cells in the generic tacrolimus group remained the same after LDLT, but absolute cell counts of $\gamma \delta \mathrm{T}$ cells in the brand-name tacrolimus group increased after 8 weeks. In subgroup analysis, absolute cell counts of V $\delta 1$ and $V \delta 2 \gamma \delta \mathrm{T}$ cells in the brand-name tacrolimus group were increased after 8 weeks. However, $\mathrm{V} \delta 1 / \mathrm{V} \delta 2$ ratio in the generic tacrolimus group was higher than in the brand-name tacrolimus group (Fig. 2).

Absolute cell counts of CD3-CD56+ $\mathrm{T}$ cells in the brand-name tacrolimus group were higher than in the generic tacrolimus group after 8 weeks. Similarly, absolute cell counts of CD4+Foxp3+ T cells in the brandname tacrolimus group were higher than in the generic tacrolimus group after 8 weeks (Fig. 3).

\section{Discussion}

In this study, the levels of CD4+Foxp3+ and CD3$\mathrm{CD} 56+\mathrm{T}$ cells were higher in the brand-name tacrolimus group than in the generic tacrolimus group 8 weeks after 
transplantation. These findings indicate that brand-name tacrolimus could have more potential as an immunosuppressant than generic tacrolimus because CD4+Foxp3+ $\mathrm{T}$ cells are related to graft tolerance. However, there were no statistically significant differences in CD3, CD4, CD8, or $\gamma \delta \mathrm{T}$ cells between the brand-name and the generic tacrolimus groups.

Our study revealed that the median $V \delta 1 / V \delta 2$ ratio in the generic tacrolimus group were more than 0.2 at each time, but median V $\delta 1 / \mathrm{V} \delta 2$ ratio in the brand-name tacrolimus group was below 0.2 at those times (Fig. 2). The present study revealed that the $\mathrm{V} \delta 1 / \mathrm{V} \delta 2$ ratio in the generic tacrolimus group was a little higher than in the brand-name tacrolimus group, but there was no statistically significant difference between the 2 groups. Although there was no statistically significant difference between the 2 groups, the present study demonstrated that brand-name tacrolimus induced an increase in $\mathrm{V} \delta 1 \gamma \delta \mathrm{T}$ cells after 8 weeks compared to the generic tacrolimus group. $\gamma \delta \mathrm{T}$ cells possess immunoregulatory function; thus, increased number of circulating $\gamma \delta \mathrm{T}$ cells were observed in patients with stable graft function $[7,14-16]$. Tolerant liver recipients show an apparent alteration in the peripheral blood $\gamma \delta \mathrm{T}$ cell subsets, thus exhibiting an elevation of $\mathrm{V} \delta 1 \gamma \delta \mathrm{T}$ cells and a distinct increase of the $\mathrm{V} \delta 1 / \mathrm{V} \delta 2$ ratio $[14,16,20]$. A recent study demonstrated an elevated $\mathrm{V} \delta 1 / \mathrm{V} \delta 2$ ratio in tolerant pediatric semiallogeneic recipients as compared to maintenance immunosuppressive and chronic rejection recipients [21].

Our findings revealed that CD4+Foxp $3+\mathrm{T}$ cells in the brand-name tacrolimus group were higher than in the generic tacrolimus group 8 and 12 weeks after transplantation. These observations suggest that brand-name tacrolimus might protect against liver allograft rejection and induce the effect of tolerance compared to generic tacrolimus. Tregs are a well-characterized T CD4+ cell subpopulation defined on the basis of constitutive expression of high levels of IL-2 receptor- $\alpha$ chain (CD25), cytotoxic T lymphocyte-associated antigen 4 (CTLA-4), and forkhead/winged helix transcription factor P3 (FoxP3) [22, 23]. Tregs play a central role in the induction of immunological tolerance after organ transplantation [22, 23]. Currently, immunosuppressive agents used in clinical practice potentially affect Treg cell populations [22, 24].

Regulatory approval for generic drugs is dependent on the demonstration of bioequivalence [3]. However, the pharmacokinetic properties of tacrolimus are affected by a number of patient-related variables, such as gut function, concomitant medication, and liver function [3]. Although generic tacrolimus may lead to improved adher-

Brand-Name and Generic Tacrolimus ence to immunosuppression and better health outcomes for transplant recipients, patients and health care providers should monitor tacrolimus trough levels more often if a recipient is switched to generic tacrolimus $[3,25]$.

The present study had several limitations that included (1) a small patient population that had selection bias and (2) the T effector cells were not analyzed. The T effector cell/Treg balance is crucial for the initiation and progression of the graft rejection response. Therefore, an ideal approach to promote tolerance could be to deplete or minimize alloreactive $\mathrm{T}$ effector cells. (3) The T-cell changes in the peripheral blood did not necessarily reflect their respective values in liver tissue. (4) Only absolute cell counts in the $\mathrm{T}$ cell population were analyzed. (5) There was a lack of any evidence of molecular-based data; therefore, the mechanism of the effect of $\mathrm{T}$ cells by brand-name or generic tacrolimus could not be proved.

\section{Conclusions}

In this study the CD3-CD56+ and CD4+Foxp3+ T cells in the brand-name tacrolimus group were higher than in the generic tacrolimus group in the peripheral blood T-cell populations in stable liver transplant recipients. This finding could indicate that brand-name tacrolimus might have more potential immunosuppressive activity than generic tacrolimus. Future studies monitoring the immune status of liver transplant recipients in relation to the type, number, and function of $\mathrm{T}$ cells are recommended to elucidate these issues in clinical liver transplantation.

\section{Disclosure Statement}

The authors declare no conflicts of interest.

References

$1 \mathrm{Gu} \mathrm{J}, \mathrm{Wu}$ X, Lu L, et al: Role of steroid minimization in the tacrolimus-based immunosuppressive regimen for liver transplant recipients: a systematic review and meta-analysis of prospective randomized controlled trials. Hepatol Int 2014;8:198-215.

2 Li XC, Turka LA: An update on regulatory T cells in transplant tolerance and rejection. Nat Rev Nephrol 2010;6:577-583.

3 Molnar AO, Fergusson D, Tsampalieros AK, et al: Generic immunosuppression in solid organ transplantation: systematic review and meta-analysis. BMJ 2015;350:h3163. 
4 Spence MM, Nguyen LM, Hui RL, et al: Evaluation of clinical and safety outcomes associated with conversion from brand-name to generic tacrolimus in transplant recipients enrolled in an integrated health care system. Pharmacotherapy 2012;32:981-987.

5 Taube D, Jones G, O’Beirne J, et al: Generic tacrolimus in solid organ transplantation. Clin Transplant 2014;28:623-632.

$6 \mathrm{Al}$ Ameri MN, Whittaker C, Tucker A, et al: A survey to determine the views of renal transplant patients on generic substitution in the UK. Transpl Int 2011;24:770-779.

7 Kalyan S, Kabelitz D: Defining the nature of human $\gamma \delta$ T cells: a biographical sketch of the highly empathetic. Cell Mol Immunol 2013; 10:21-29.

8 Illigens BM, Yamada A, Anosova N, et al: Dual effects of the alloresponse by Th1 and Th2 cells on acute and chronic rejection of allotransplants. Eur J Immunol 2009;39:30003009.

9 Pham B, Piard-Ruster K, Silva R, et al: Changes in natural killer cell subsets in pediatric liver transplant recipients. Pediatr Transplant 2012;16:176-182.

10 Liu Y, Luan X, Li J, et al: The role of invariant NKT cells in liver transplant tolerance in rats. Transplant Proc 2012;44:1041-1044.
11 Li Y, Zhao X, Cheng D, et al: The presence of Foxp3 expressing T cells within grafts of tolerant human liver transplant recipients. Transplantation 2008;86:1837-1843.

12 Abadja F, Sarraj B, Ansari MJ: Significance of $\mathrm{T}$ helper 17 immunity in transplantation. Curr Opin Organ Transplant 2012;17:8-14.

13 Malone F, Carper K, Reyes J, et al: $\gamma \delta \mathrm{T}$ cells are involved in liver transplant tolerance. Transplant Proc 2009;41:233-235.

14 Puig-Pey I, Bohne F, Benitez C, et al: Characterization of $\gamma \delta$ T cell subsets in organ transplantation. Transpl Int 2010;23:1045-1055.

15 Koshiba T, Li Y, Takemura M, et al: Clinical, immunological, and pathological aspects of operational tolerance after pediatric livingdonor liver transplantation. Transpl Immunol 2007;17:94-97.

16 Martínez-Llordella M, Puig-Pey I, Orlando G, et al: Multiparameter immune profiling of operational tolerance in liver transplantation. Am J Transplant 2007;7:309-319.

17 Yu YD, Lee SG, Joh JW, et al: Results of a phase 4 trial of Tacrobell ${ }^{\circledR}$ in liver transplantation patients: a multicenter study in South Korea. Hepatogastroenterology 2012;59:357363.

18 Kim JM, Kim GS, Joh JW, et al: Long-term results for living donor liver transplant recipients with hepatocellular carcinoma using intraoperative blood salvage with leukocyte depletion filter. Transpl Int 2013;26:84-89.
19 Human and Mouse CD Marker Handbook. 2010. http://www.bdbiosciences.com/documents/cd_marker_handbook.pdf (accessed Oct 1, 2016).

20 Li Y, Koshiba T, Yoshizawa A, et al: Analyses of peripheral blood mononuclear cells in operational tolerance after pediatric living donor liver transplantation. Am J Transplant 2004;4:2118-2125.

21 Zhao X, Li Y, Ohe H, et al: Intragraft $V \delta 1 \gamma \delta$ $\mathrm{T}$ cells with a unique T-cell receptor are closely associated with pediatric semiallogeneic liver transplant tolerance. Transplantation 2013;95:192-202.

22 Boros P, Bromberg IS: Human FOXP3+ regulatory $\mathrm{T}$ cells in transplantation. Am J Transplant 2009;9:1719-1724.

23 Sakaguchi S, Yamaguchi T, Nomura T, et al: Regulatory $\mathrm{T}$ cells and immune tolerance. Cell 2008;133:775-787.

24 Demirkiran A, Hendrikx TK, Baan CC, et al: Impact of immunosuppressive drugs on $\mathrm{CD} 4+\mathrm{CD} 25+\mathrm{FOXP} 3+$ regulatory $\mathrm{T}$ cells: does in vitro evidence translate to the clinical setting? Transplantation 2008;85:783-789.

25 van Gelder T; ESOT Committee on Generic Substitution: European Society for Organ Transplantation Advisory Committee recommendations on generic substitution of immunosuppressive drugs. Transpl Int 2011;24: 1135-1141. 